\title{
ANÁLISE DA AUTOMEDICAÇÃO DURANTE A PANDEMIA DO NOVO CORONAVÍRUS: UM OLHAR SOBRE A AZITROMICINA
}

\author{
ANALYSIS OF SELF-MEDICATION DURING THE NEW CORONAVIRUS PANDEMIC: \\ A VIEW ON AZITHROMYCIN
}

\author{
Washington de Souza Leal ${ }^{1}$ \\ Delizete Nascimento Alves Melo ${ }^{2}$ \\ Fillipe Cássio Souza Silva ${ }^{3}$ \\ Kelvin Alves Nazaré 4 \\ Bruna Talia Ferreira Rodrigues ${ }^{5}$ \\ Ester Louzada Fernandes ${ }^{6}$ \\ Maria Eloisa da Silva Araújo ${ }^{7}$ \\ Junia Lara Martins ${ }^{8}$ \\ Lorran Miranda Andrade de Freitas ${ }^{9}$
}

RESUMO: Recentemente uma doença causada por um novo coronavírus, o SARS-CoV2, foi descrita como COVID-I9, e se espalhou obtendo o caráter pandêmico. Com a disseminação viral e consequente elevação no número de mortes em todo o mundo, houve uma crescente ascensão na divulgação de notícias origem profilática. Concomitantemente, notou-se um crescimento na curva de automedicação por indivíduos, em grande parte, influenciados por notícias falsas disponibilizadas em mídias sociais e em debates sem embasamento científico. Neste sentido, um fármaco que se evidencia é a Azitromicina, um antibiótico do tipo azalida, que foi amplamente prescrita e utilizada em larga escala pela população em geral. Pretende-se com este trabalho debater sobre o aumento da automedicação durante este período pandêmico, enfatizando o uso indiscriminado da Azitromicina, além de ressaltar os fatores que contribuem para tal prática que corroboram para o aumento da resistência bacteriana.A automedicação traz consigo diversos perigos, entre eles os efeitos colaterais ocasionados pela interação medicamentosa ou alimentar, o que eleva o número de comorbidades e mortalidades em tempos de pandemia, além de exercer uma pressão negativa sobre os microrganismos contribuindo para uma seleção natural de bactérias resistentes aos antimicrobianos.

Palavras chave: Covid-ıg. Automedicação. Azitromicina.

\footnotetext{
${ }^{1}$ Discente do curso de Biomedicina da Faculdade Única de Ipatinga (FUNIP) washingtonds48@gmail.com

${ }^{2}$ Discente do curso de Biomedicina da Faculdade Única de Ipatinga.deli.nascimento.alves@gmail.com

${ }_{3}$ Discente do curso de Biomedicina da Faculdade Única de Ipatinga (FUNIP) filipecassioo7@gmail.com

${ }^{4}$ Discente do curso de Biomedicina da Faculdade Única de Ipatinga (FUNIP) alveskbmd@gmail.com

5 Discente do curso de Biomedicina da Faculdade Única de Ipatinga (FUNIP) bruna.taliar25@hotmail.com

${ }^{6}$ Discente do curso de Biomedicina da Faculdade Única de Ipatinga (FUNIP) esterlfernandes@hotmail.com

${ }_{7}$ Discente do curso de Biomedicina da Faculdade Única de Ipatinga (FUNIP) mariar23186@outlook.com

${ }^{8}$ Discente do curso de Biomedicina da Faculdade Única de Ipatinga (FUNIP) junialara@hotmail.com

${ }^{9}$ Docente do curso de Biomedicina da Faculdade Única de Ipatinga (FUNIP) lorranmiranda@hotmail.com
} 
ABSTRACT: Recently, a disease caused by a new coronavirus, SARS-CoV2, was obtained as COVID-I9, and it spread with a pandemic character. With the viral spread and the consequent increase in the number of deaths worldwide, there was a growing rise in the dissemination of news of prophylactic origin. Concomitantly, there was an increase in the self-medication curve, largely influenced by false news available on social media and in debates with no scientific basis. In this sense, one drug that stands out is azithromycin, an azalide-type antibiotic, which has been widely prescribed and used on a large scale by the general population. The aim of this paper is to discuss the increase in self-medication during this pandemic period, emphasizing the indiscriminate use of Azithromycin, in addition to highlighting the factors that contribute to this practice that corroborate the increase in bacterial resistance. Self-medication brings with it several dangers, including the effects caused by drug or food interaction, which increases the number of comorbidities and mortality in times of pandemic, in addition to exerting a negative pressure on microorganisms contributing to a natural selection of bacteria resistant to antimicrobials.

Keywords: Covid-19. Self-medication. Azithromyci

\section{INTRODUÇÃO}

Em dezembro de 2019, uma doença causada por um novo coronavírus, o SARS$\mathrm{CoV}_{2}$, se espalhou desde a sua origem por muitos países ao redor do mundo, provocando altos índices de morbimortalidade em escala mundial. Com a emergência internacional, posteriormente, foi declarada a pandemia do COVID-I9, em março de 2020. Diante da grande repercussão sobre a atual pandemia, vem se observando o comportamento de indivíduos em automedicar-se, muitas das vezes influenciados por notícias falsas disponibilizadas em mídias de TV, sites e redes sociais, sendo na maioria das vezes, informações sem qualquer embasamento científico².

A automedicação é tratada pelo indivíduo como um autocuidado. Entretanto, tal prática tem potencial risco de evocar consequências danosas à saúde, referida como um grave problema de saúde pública ${ }^{3}$. Wong ${ }^{4}$ complementa que no atual cenário da pandemia causada pelo COVID-ı9, a automedicação se tornou um risco potencial, dando exemplo da utilização da azitromicina, que em sobre dosagem ou em indivíduos que são susceptíveis, podem causar alterações hepáticas e renais.

A azitromicina é um antibiótico muito utilizado no combate á infecções bacterianas, e faz parte da família dos macrolídeos apresentando ainda atividade antiviral e imunomoduladora. Existem muitas vias que suportam o potencial mecanismo de atuação da atividade imunomoduladora da azitromicina, que se dá através da supressão da ativação das células linfócito $\mathrm{T}$ helper $\mathrm{CD}_{4+}\left(\mathrm{Th} \mathrm{CD}_{4+}\right)$, redução da produção de citocinas próinflamatórias (interleucina IL-r $\beta$, interleucina IL-6, interleucina IL-8, interleucina IL-I2, interferon gamaIFN- $\gamma$, fator de necrose tumoral alfaTNF- $\alpha$, fator estimulador de colônia de granulócitos-macrófagosGM-CSF), além da mudança na polarização para fenótipo antiinflamatório e aumento do apoptose em macrófagos alveolares 5 .

Existem também, registros sobre a atividade antifibrótica da azitromicina através da redução na síntese de colágeno e inibição na proliferação de fibroblastos. Além disto, em 
células epiteliais a azitromicina possui a atividade inibitória da hipersecreção de muco, auxiliando na depuração mucociliar ${ }^{6}$. Quanto a atividade antiviral, neste contexto pandêmico, seus mecanismos de ação incluem a ligação da droga ao local de ligação ao gangliosídeo, disposto na proteína Spike do SARS-COV2, além de interferir no receptor cluster de diferenciação 147 (CDi47) do ligante, e outro mecanismo antiviral ocorre através de um aumento no potencial hidrogeniônico $(\mathrm{pH})$ lisossomal, provocando um prejuízo na atividade das catepsinasclivadoras da proteína $\mathrm{S}$, prejudicando o processo de endocitose ${ }^{7}$

A utilização inadequada da azitromicina pode causar um aumento significativo na taxa de resistência bacteriana, atingindo grandes dimensões no contexto da pandemia ${ }^{8}$. Segundo Júnior ${ }^{9}$, os antibióticos reduzem a taxa de mobimortalidade por infecções bacterianas em escala global, mas que com o passar do tempo, o aumento de casos de resistência bacteriana aos antimicrobianos tem se elevado, tornando necessárias elaborações de medidas preventivas, visando à melhoria e minimização dos efeitos da resistência bacteriana, assim como evitar novas cepas multirresistentes.

Analisando esta abordagem, pode-se compreender que o uso indiscriminado de antibióticos é considerado o principal fator para o desenvolvimento da resistência bacteriana, muitas vezes ocasionado pela falta de conhecimento de quem faz o uso ou pela dificuldade de acesso aos serviços de saúde, o que leva o indivíduo a automedicação ${ }^{\mathrm{Io}}$. Segundo Saldanha, Souza e Ribeiro ${ }^{\text {II, }}$ o aumento da resistência bacteriana causa grandes impactos, principalmente em áreas hospitalares, uma vez que aumentam o número de morbimortalidades e eleva os gastos dos serviços de saúde, sendo assim, a educação populacional sobre o consumo consciente de antibióticos são de suma importância para combater esse problema. Diante deste esclarecimento, objetivamos com este trabalho, realizar um estudo de revisão sobre a resistência à azitromicina promovida pela utilização indiscriminada durante a pandemia do COVID-I9.

\section{METODOLOGIA}

O presente estudo trata-se de uma revisão da literatura sobre a resistência à azitromicina promovida pela utilização indiscriminada durante a pandemia do COVID-I9. Para a realização da revisão bibliográfica utilizamos livros e artigos indexados entre os anos de 2010 a 202I, por redes de busca como a Biblioteca Virtual em Saúde (BVS), ScientificElectronic Library Online (Scielo), ScienceDirect, PubMed e Google Acadêmico. Este método de estudo tem grande relevância para pesquisa, pois permite a síntese e conclusões gerais sobre o problema apresentado e suas consequências para a saúde pública, além de possibilitar um alcance maior de informação, apontando possíveis lacunas que motivam a realização dos novos estudos sobre a automedicação e a resistência bacteriana. Pretende-se com este trabalho expandir o conhecimento sobre a COVID-19, a azitromicina e a automedicação, buscando obter uma melhor compreensão sobre a resistência bacteriana e suas complicações. Os critérios de inclusão adotados foram: estudos relevantes para os objetivos propostos, publicados de preferência nos últimos seis anos, nos idiomas português e inglês. Textos com mais de seis anos de publicação, somente foram utilizados artigos originais com informações essenciais para o estudo. Os descritores para a pesquisa foram os termos: azitromicina, COVID-ıg e automedicação. 


\section{DISCUSSÃO}

\section{I Azitromicina}

A azitromicina é um antibiótico do tipo azalida e proveniente da eritromicina. Contém uma substituição de um grupo carbonil por um grupo metil, formando assim o anel lactona com is carbonos, ${ }^{12}$ que pertence ao grupo dos macrolídeos. Estes agentes bacteriostáticos atuam se ligando a trechos específicos do RNA ribossomal bacteriano, interferindo no processo de elongação da cadeia peptídica durante a translação e embargando o processo antes que a síntese proteica seja concluída pela bactéria. ${ }^{13}$ Além de bacteriostático, a azitromicina também pode atuar de forma bactericida a depender de algumas características, dentre elas as concentrações plasmáticas e teciduais. ${ }^{\mathrm{I}}$

Devido à ampla variedade de casos onde a azitromicina é utilizada, tanto como uma primeira opção, quanto como uma alternativa de tratamento, ela pode ser considerada um medicamento versátil. ${ }^{15}$ Esse fármaco possui um papel imunomodulador muito importante, ao contribuir para a preservação da estrutura tecidual sem comprometer a resposta do sistema imune e sem induzir efeitos colaterais consideráveis. Além disto, a azitromicina também atua na prevenção de infecções bacterianas oportunistas, em decorrência da sua ação bacteriostática. ${ }^{16}$ Dentre os casos em que o uso da azitromicina é recomendado, podemos citar o tratamento de tracoma e de algumas infecções sexualmente transmissíveis (ISTs), como uretrite e cervicite, ambas relacionadas ao Chlamydiatrachomatis, tendo como alternativa à penicilina e à clindamicina nos tratamentos onde o uso destes é inviável devido a reações alérgicas. ${ }^{17}$

Corrêa e Fukushima (2020) analisaram os resultados encontrados por 16 artigos sobre a atividade antiviral da azitromicina e, dentre 12 destes artigos, o medicamento se mostrou eficaz contra zika vírus, rinovírus, influenza A e enterovírus Ai7.Também apresentou atividade antiviral contra o vírus ebola, embora não tenha sido eficaz no tratamento como esperado. De tal forma, apesar de fortes indícios de um potencial atividade antiviral da azitromicina, esta temática ainda carece de mais estudos.

\subsection{Mecanismo de ação da Azitromicina}

Iriarte descreve que a síntese proteica envolvendo organismos procariontes ou eucariontes é realizada por meio de uma transcrição do DNA e que este processo será concluído nos ribossomos, onde uma organela será formada por proteínas e RNA, que pode variar em relação a sua conformação e tamanho entre os possíveis níveis de estrutura celular. Essa diferenciação ocorre por meio das modificações de suas estruturas, confere por uma seletividade fundamental em sua atuação devido os fármacos verificar a quimiotoxicidade dos patógenos ${ }^{19}$.

$\mathrm{Na}$ absorção por via oral, a azitromicina é distribuída pelo corpo e aproximadamente $37 \%$ está presente na etapa de biodisponibilidade, sua distribuição acontece de acordo com o tempo de alcançar a maior concentração plasmática, normalmente entre duas a três horas, sua meia-vida plasmática é de dois a quatro dias. Sabe-se que biotransformação do fármaco se encontra maior nos tecidos com a presença de altas 
concentrações no interior das células e em sua eliminação o fármaco sofre o metabolismo hepático em metabolitos inativos, sendo excretado em sua forma inalterada pela urina ${ }^{20}$.

O mecanismo de ação da azitromicina sucede por meio da inibição que ocorre na síntese proteica de RNA, mediante uma ligação nos receptores encontrados na porção $50 \mathrm{~S}$ do ribossomo, principalmente na molécula da porção ${ }_{23} \mathrm{~S}$ do RNA, resultando em um impedimento nas reações de translocação e transpeptidação. Já o mecanismo de resistência pode surgir devido ao decrescimento que acontece na permeabilidade da própria célula ao antimicrobiano, ou por meio de alterações no sítio receptor da porção soS até chegar na inativação enzimática ${ }^{21}$.

Este bloqueio dificulta que o peptidil-RNAr dê sequência na fase de translocação da cadeia peptídica e impede a liberação do sítio ribossômico e sua inserção da amina no anelmacrocíclico, proporcionando a molécula uma melhor ação em meio ácido e possibilitando um alto índice de concentração tecidual, diminuindo os efeitos adversos da classe ${ }^{19}$.

Ferner e Aronson relatam que a azitromicina pertence ao grupo dos macrolídeos caracterizados pelos antimicrobianos quimicamente compostos por um anel macrocíclico de lactona, que vai atuar por meio da junção de apenas um ou mais açúcares, que podem diminuir a produção de interleucina -6 (IL-6) in vitro, fazendo com que o fármaco possa se acumular no fluido pulmonar. Existem mecanismos de resistência bacteriana contra os macrolídeos que dificultam o acesso do antibiótico ao sítio efetor ou inativam a molécula, sendo a principal delas relacionada à alteração do alvo efetor nos ribossomos. As bactérias por meio do gene realizam a desmetilação do nucleotídeo adenina da porção ${ }_{23} \mathrm{~S}$, modificando sua conformação que consequentemente impedi que o macrolídeo se ligue ao ribossomo ${ }^{22}$.

\section{I.2 Mecanismo de aquisição da resistência bacteriana}

Os antibióticos estão entre os principais medicamentos prescritos em todo o mundo, no entanto, frequentemente é desnecessário ou inapropriado. Efeitos adversos relacionados aos medicamentos, acontecem sobretudo no trato gastrointestinal, incluindo diarreia, interação medicamentosa de antibióticos com outros medicamentos, como por exemplo, na polifarmácia, com destaque para as consequências relacionadas ao uso indiscriminado de antibióticos, que podem resultar em resistência bacteriana ${ }^{\text {io }}$.

Teixeira, Figueiredo e França ${ }^{22}$, declaram que a resistência bacteriana é um problema mundial, a OMS (Organização Mundial da Saúde) relata a preocupação e alerta que milhões de mortes ocorrerão por bactérias resistentes. Portanto a indicação do uso de antibióticos deve ser estritamente médica e a automedicação deve ser evitada, entretanto o antibiótico é importante e fundamental para salvar vidas, porém sua utilização deve ser criteriosa e apropriada.

A definição de bactéria resistente é a capacidade de crescer in vitro, nas concentrações do que o antibiótico atingiria no sangue quando administrado por via oral no ser humano. Existem dois tipos de resistência bacteriana, a intrínseca que é inerente a bactéria, ou seja, resistência natural de um gênero ou espécie bacteriana, e resistência adquirida, onde se origina por mutações nos próprios genes ou pela obtenção dos genes de resistência de outras bactérias, sendo por via de conjugação plasmídeo ou transposon, via bacteriófago transdução, e via ambiente, transformação 9 . 
Costa e Junior ${ }^{23}$, discorrem que o mecanismo de resistência bacteriana acontece quando a bactéria consegue modificar a forma que o antibiótico atua, produzindo enzimas capazes de destruir ou modificar o antibiótico, também podem fazer bomba de fluxo, simplesmente expulsam o antibiótico para o meio extracelular, ou podem fazer modificações estruturais, como por exemplo, os antibióticos que atuam na síntese proteica, podem mutar o sítio de ligação do antibiótico, a subunidade do ribossomo de forma que o antibiótico não consiga conhecer e nem se ligar a determinadas estruturas. Uma das principais consequências desses mecanismos de defesa, juntamente com o uso indiscriminado de antibióticos é o surgimento das bactérias super-resistentes, que assustadoramente são resistentes a todos os antibióticos existentes ${ }^{24}$.

\subsection{Relação da pandemia com o aumento da automedicação}

Os medicamentos são compostos fundamentais a saúde e um grande instrumento terapêutico para o profissional que o prescreve, porém quando utilizado de forma inadequada e sem conhecimento podem gerar impactos negativos para a vida do indivíduo ${ }^{25}$. Júnior e Salvi (2018) ${ }^{3}$ complementam que o hábito de se automedicar é compreendido como o uso de um medicamento sem a devida orientação de um profissional habilitado, sendo muito comum entre a população, representando um grande risco a saúde em escala global.

De Freitas Silva (202I), relata que os medicamentos mais procurados pelo consumidor são os analgésicos, antibióticos, antifúngicos e antioxidantes, dentre eles estão; paracetamol, azitromicina, antirretrovirais, ivermectina cloroquina e hidroxicloroquina, penicilina, dipirona e vitamina C. Souza et. al (2021) ${ }^{26}$ realizou uma pesquisa onde, $(30,1 \%)$ dos participantes afirmam realizar a automedicação com o intuito de prevenir ou tratar a infecção pelo SARS-CoV-2, dentre eles 14,2\% fizeram a automedicação da azitromicina.

Vários fatores influenciam a população nesta prática, como a falta de acesso aos meios de saúde e a influência da propaganda feita sobre os medicamentos de venda livre, incentivando cada vez mais a automedicação, uma vez que boa parte da população cria uma ideia errada por meio da propaganda, acreditando que estes medicamentos sem receita não são prejudiciais à vida 27 . Seguindo as regras básicas, a propaganda pode apresentar apenas os medicamentos que não necessitam de prescrição médica, e em sua maioria são mostrados apenas seus benefícios, omitindo informações importantes sobre a segurança do mesmo ${ }^{28}$.

A utilização de medicamentos forma indiscriminada pode levar o indivíduo a complicações graves e o surgimento de conflitos que atualmente são considerados um grande problema para saúde pública ${ }^{29}$. Loureiro et al (2016) ${ }^{30}$ citam que um grande número de pessoas faz o uso dos antibióticos sem orientação médica, contribuindo para a resistência bacteriana, sendo as grandes responsáveis por consequências clínicas e econômicas, relacionadas ao aumento da morbidade e mortalidade. Além da resistência bacteriana, o uso indiscriminado de fármacos expõe o indivíduo ao risco de intoxicação que constitui uma variedade de sintomas causados pela forma de administração, podendo ser classificadas em agudas ou crônicas, e cada droga irá apresentar um quadro de sinais e sintomas diferentes ${ }^{31 .}$

Atualmente, com a desinformação que gera o aumento do uso irracional de alguns medicamentos e o não cumprimento do isolamento, é uma adversidade que gera o atraso no combate do COVID-ı, como é o caso da azitromicina, que é utilizado juntamente com a hidroxicloroquina e a cloroquina para tratar e prevenir contra o vírus, definidos por grupos políticos e por líderes mundiais, influenciando logo em seguida o aumento da prática da automedicação. A Agência Nacional de Vigilância Sanitária (ANVISA) delimitou a venda 
destes remédios sem a receita medica, o que contribui para um aumento espontâneo da automedicação por azitromicina ${ }^{32}$.

Sabe-se, portanto, que diversos fatores contribuíram para esse aumento tão expressivo. Um dos fatores mais importantes a ser citado é a politização da pandemia, uma vez que na tentativa de encontrar uma solução rápida e já existente, diversos líderes no mundo passaram a apoiar a utilização de determinadas drogas para manejo da doença, sendo muitas delas sem qualquer comprovação científica ou conhecimentos da farmacotoxicologia 33 .

Segundo Melo e colaboradores (202I) 22, a azitromicina teve suas vendas aquecidas, apresentando um aumento de 30,8 \% nas vendas e crescendo a movimentação dos caixas nacionais. Com o crescimento da renda desse medicamento, ampliaram-se às decorrências resultantes dele, tais como a resistência bacteriana e reações adversas, de tal maneira que se apresenta sérios riscos. Conceição $(2020)^{7}$, cita que há um ocasionando alterações cardiológica que correlaciona com uma probabilidade maior de arritmias ventriculares, potencialmente fatais, interferindo no metabolismo, sistema imune, psiquiátrico e oculares.

Este resultado no resultado no Brasil foi uma avalanche de incertezas levando a população a recorrer mesmo sem precedentes para as farmácias. E com base em analises também se observou que durante este elevado índice do consumo da azitromicina, houve uma das fases mais críticas da pandemia no Brasil (MELO et al, 202I) ${ }^{22}$.

Além disto, observou-se um aumento do negacionismo quanto a difusão do conhecimento científico baseado em evidências, atos de desinformação e compartilhamento de notícias falsas, colocando a população exposta a possibilidade de causar efeitos nocivos (SILVA et al, 2021) ${ }^{37}$.

Malik et al (2020) ${ }^{20}$, complementam que durante a pandemia do COVID-I9 ocorreu um aumento alarmante na utilização de medicamentos em busca da melhora de sintomas relacionados a doenças conhecidas, uma vez que, o acesso as redes sociais aumentaram durante este período e muitas informações que são repassadas por estas redes não condiz com a realidade ou omitem informações que são essenciais para o indivíduo. A automedicação traz consigo diversos perigos, entre eles os efeitos colaterais ocasionados pela interação medicamentosa ou alimentar, o que eleva o número de comorbidades e mortalidades em tempos de pandemia, uma vez que, o sistema de saúde se encontra engajado no combate da COVID-ı9 (MAKOWSKA et al., 2020) ${ }^{19}$.

A preocupação pública se mostrou durante o número crescente da compra de medicamentos com medo alimentado pelas mídias sociais afetando a saúde psicológica do indivíduo, fator que eleva a automedicação, incluindo a utilização de substâncias como álcool e outras drogas, podendo haver a interação destes (ZHANG et al., 20II) ${ }^{42}$. Sadio e colaboradores $(2020)^{34}$ complementam que a pandemia generalizou um estado de ansiedade na população, que está diretamente ligado a alta taxa de mortalidade que pode ser observada em diversos países, uma vez que ainda não possuímos uma cura efetiva contra a COVID19, e que pela variedade de informações que vem circulando nas mídias sociais, plantas e substancias sem requisitos necessários para uma eficácia ou tolerância estão sendo utilizadas em algumas regiões, sendo assim considerada como automedicação.

Oliveira et al (202I) ${ }^{24}$ complementam que a falta de medicamentos que atuem diretamente contra a COVID-ı tem-se elevado o comportamento da automedicação, intensificando a procura de suplementos alimentares e vitaminas que estimulem a imunidade e ajude a prevenir contra o vírus, assim como os antibióticos. Alguns antibióticos possuem um custo muito elevado, sendo um fator para uma baixa prevalência na utilização 
de alguns fármacos, porém existem grupos que fazem a utilização destes como tratamento profilático para prevenção, mesmo assim, esta prática e mais comum em países cujo o sistema de saúde são menos eficazes, com longos prazos de espera, estoque insuficiente, a falta de atenção com paciente e quantidade baixa de leitos disponíveis.

O COVID-ig foi identificado no final de 2019 e rapidamente se espalhou por todo o mundo, causando comorbidades e mortalidades, gerando uma grande preocupação para as pessoas quanto ao risco pessoal que cada uma estaria exposta, colocando a população em um estado vulnerável, o que incentivou muito na automedicação (CRUZ et al., 202I) ${ }^{\text {Io }}$. Mejía, Gerrero e Chero (2020) ${ }^{21}$, realizaram um estudo que apresentou características da automedicação em fase anterior e posterior da COVID-ı, mostrando um aumento nesta prática, apresentando comorbidades frequentes dentro de uma população que se automedica, destacando a hipertensão $(24,8 \%)$, sobrepeso / obesidade $(6,5 \%)$, diabetes $(3,6 \%)$ e câncer $(2,4 \%)$, e as demais relataram não ter comorbidades $(32,5 \%)$, estar se automedicaram por sinais ou sintomas de gripe e dores de cabeça (Tabela I).

Tabelar: Características da população que se automedica antes e durante o COVID-19

\begin{tabular}{|c|c|c|c|}
\hline Característica & $\begin{array}{c}\text { Automedicação antes } \\
\text { da pandemia }\end{array}$ & $\begin{array}{c}\text { Automedicação } \\
\text { durante a pandemia }\end{array}$ & Valores \\
\hline Idade & 46,50 anos & 40,87 anos & 0,022 \\
\hline \multicolumn{4}{|l|}{ Sexo } \\
\hline Masculino & $303(72,8 \%)$ & $38 \mathrm{I}(48,2 \%)$ & \multirow[b]{2}{*}{ o,oor } \\
\hline Feminino & $\mathrm{II} 3(27,2 \%)$ & $409(51,8 \%)$ & \\
\hline \multicolumn{4}{|l|}{ Grau de Instituição } \\
\hline Primária/Secundária & $263(63,2 \%)$ & $482(61,0 \%)$ & \multirow{2}{*}{0,056} \\
\hline Superior & $153(36,8 \%)$ & $308(39,0 \%)$ & \\
\hline \multicolumn{4}{|l|}{ Pessoal de Saúde } \\
\hline Sim & $23(5,5 \%)$ & $45(5,7 \%)$ & \multirow{2}{*}{0,783} \\
\hline Não & $393(94,5 \%)$ & $745(93,3 \%)$ & \\
\hline \multicolumn{4}{|l|}{ Comorbidades } \\
\hline Nenhuma & $135(32,5 \%)$ & $337(42,7 \%)$ & 0,017 \\
\hline HTA & $103(24,8 \%)$ & $\mathrm{I} 22(\mathrm{I} 5,4 \%)$ & 0,032 \\
\hline Sobrepeso/Obesidade & $27(6,5 \%)$ & $108(13,7 \%)$ & o,oor \\
\hline Diabetes & I5 $(3,6 \%)$ & $56(7,1 \%)$ & 0,023 \\
\hline Câncer & Io $(2,4 \%)$ & $36(4,6 \%)$ & 0,039 \\
\hline Doença Cardiovascular & $9(2,2 \%)$ & $23(2,9 \%)$ & 0,332 \\
\hline Doença Pulmonar & $8(\mathrm{I}, 9 \%)$ & $23(2,9 \%)$ & 0,13 \\
\hline Insuficiência Renal & $7(\mathrm{I}, 7 \%)$ & $22(2,8 \%)$ & 0,089 \\
\hline $\begin{array}{l}\text { Doença ou tratamento } \\
\text { Imunossupressor }\end{array}$ & $7(1,7 \%)$ & $18(2,3 \%)$ & 0,409 \\
\hline
\end{tabular}




$\begin{array}{lccc}\text { Asma } & 7(1,7 \%) & 17(2,2 \%) & 0,22, \\ \text { Outros } & 88(21,2 \%) & 28(3,5 \%) & \text { o,ooor }\end{array}$

Fonte: MEJÍRA.P.J. N, GERRERO.J.C.V, CHERO.L.L., Automedicação em tempos de pandemia: COVID19., Revista HNAAA Medical Corps., v.13, n⿳ำ4, p.350-355., 2020.

\section{CONSIDERAÇÕES FINAIS}

Diante do exposto, verificou-se que, a automedicação tem se tornado cada vez mais frequente neste período de pandemia. Este aumento, muitas das vezes, é devido a influência da circulação das chamadas fakenews, com um bombardeio de informações sem cunho científico, que aproveitam o contexto atual, para a divulgação de supostos medicamentos para combater o COVID-19. Atualmente, a azitromicina tem ganhado ênfase por se tratar de um antibiótico com atividade antiviral comprovada. Vale ressaltar que, diante da emergência mundial, a tentativa de recolocar fármacos já conhecidos pelos seus efeitos terapêuticos e adversos é extremamente válida. Todavia, deve-se haver cautela no desenho racional de medidas terapêuticas, considerando os diversos fatores que influenciam na necessidade e indicação do seu uso. Além disto, o alto número de mortos provoca na sociedade a insegurança, que acompanhada pelo medo, podem corroborar para automedicação na tentativa de "prevenir" o adoecimento. Dessa forma, a conscientização da população visa auxiliar no sucesso terapêuticono tratamento do COVID-ı, e ainda prevenir futuros surtos por aquisição de resistência aos antimicrobianos.

\section{REFERÊNCIAS BIBLIOGRÁFICAS}

1. Tavares TRP, Medeiros LHC. Riscos da automedicação na pandemia por COVID-ı9: o dilema entre informações midiáticas e científicas., Ciências da saúde no Brasil: contribuições para enfrentar os desafios atuais e futuros. Editora Amplla. 2020; I(I), 4046.

2. Sharma K, Seo S, Meng C, Rambhatla S, Liu Y. COVID-ı9 na mídia social: analisando desinformações em conversas no twitter. Cornell University Library 2020; 4(I), I-I3.

3. Júnior JMA, Salvi JO. Fatores associados à automedicação em uma farmácia comunitária de ouro preto do Oeste, Rondônia. ACTA Biomedicina Brasileira 2018; 9(2), Io7-Ir6.

4. Wong A. COVID-ig e toxidade de tratamentos potenciais: panaceia ou veneno. EMA Medicina de Emergência Australasia 2020. 32(I), 697-699.

5. Calderón JLM, Márquez FCL, Flores PR. Azitromicina como tratamento contra Chlamydia trachomatis? Centro de Pesquisa Biomédica - Mexico 2018; 154 (6), 689-69.

6. Finato AC. Avaliação de terapias antifibróticas associadas aos antifúngicos itraconazol e cotrimoxazol em modelo murino de paracoccidioidomicose pulmonar [dissertação]. Botocatu: Universidade Estadual Paulista "Júlio De Mesquita Filho"; 2017. 
7. Neto IFS, Ricardino IEF, Souza MNC, Mendes, R.C. Alvos moleculares dos Fármacos no tratamento da COVID-I9. Cadernos de prospecção - Salvador 2020. 13(5), I25I-I271.

8. Oliveira R, Aires T. Resistência aos antibacterianos. Artigo de revisão Gazeta Médica 2016. 3(2), I4-2I.

9. Júnior AM. Multirresistência a antibióticos em hospitais. ScireSalutis 2019. 9(2), I-8.

10. Vieira PN, Vieira SLV. Uso irracional e resistência a antibióticos em hospitais. Arquivos de ciências e da saúde da UNIPAR 2017. 2I(3), 209-212.

11. Saldanha DMS, Souza MBM, Ribeiro JF. O uso indiscriminado dos antibióticos: uma abordagem narrativa da literatura. Revista interface da saúde 2018. I(I), I2-37.

12. BAKHEIT, A.H.; AL-HADIYA, B.M.; ABD-ELGAliL, A.A. Azitromicina., Peris de metodologia e relação de substâncias medicamentosas., v.39, nํㅛ, p.I-40., 2014.

13. ADAM, A.M.A.; SAAD, H.A.; ALSUHAIBANI, A.M.; REFAT, M.S.; HEGAB, M.S. Química de transferência de carga da azitromicina, o antibiótico usado mundialmente para tratar a doença do coronavírus (COVID-19). Parte III: Um protocolo verde para síntese fácil de complexos com aceitadores TCNQ, DDQ e TFQ., Jornal de moléculas líquidas, ELSEVIER., v.355, nํำ p.I-I2.,202I

14. PANI, A.; LAURIOLA, M.; ROMANDINI, A.; SCAGLIONE, F. Macrolídeos e infecções virais: enfoque na azitromicina na patologia de COVID-I9., Jornal internacional de agentes antimicrobianos., v.56, n⿳ํㅡ, p.I-18., 2020.

15. MAKOWSKA, M.; BOGUSZEWSKI, R.; NOWAKOWSKI, M.; PODKOWINSKA, M. Comportamentos relacionados à automedicação na Polônia: confinamento da COVID-r9., Jornal Internacional de Pesquisa Ambiental e Saúde Pública., v.14, n-8344, p.I-19., 2020.

16. CORRÊA, L.T.; FUKUSHIMA, A.R. Potencial atividade antiviral da azitromicina: revisão sistemática., Revista SanarMed., v.ı, nº 3, p.97-99., 2020.

17. ODOM, J.D.; SUBRAMANIAM, A.; AARON, K J.; GEISLER, W.M.; TITA, A.T.N.; MARRAZZO, J. Altas taxas de clamídia persistente e recorrente em mulheres grávidas após o tratamento com azitromicina., Jornal americano de obstetra e ginecologia., v.2, nํㅜㄴ, p.I-8., 2020 .

18. IRIARTE, D.F. Resistência bacteriana aos macrolídeos: um olhar sobre a azitromicina., Trabalho de conclusão do curso de Medicina, Universidade Federal de São Carlos., 2020. 
19. Iriarte DF. Resistência bacteriana aosmacrolídeos: um olhar sobre a azitromicina. [monografia], São Cartos: Universidade Federal de São Carlos; 2020.

20. Berson LRS.Zitromax IV azitromicinadi-hidratada. Wyeth Indústria Farmacêutica Ltda, 2020; p. I-5.

21. Almeida FB, Cabral SAAO, Alencar MCB, Figueiredo CHA, Silveira DC, Farias WKA. Atenção farmacêutica em análises da dispensação de antimicrobianos em farmácia. Revista Brasileira de Educação e Saúde, 2010; v.5, nº 4, p.23-29.

22. Ferner RE, Aronson JK. Vinhetas de medicamentos: Azitromicina. University of Oxford, BRASIL., 2020. Disponível em URL:https://oxfordbrazilebm.com/index.php/vinhetas-de-medicamentosazitromicina/.

23. Costa ALP, Junior ACSS. Resistência bacteriana aos antibióticos e Sáude Pública: uma breve revisão de literatura. Estação Cientifica (UNIFAP) 2017; 7(2): 45-57.

24. Vieira PJL, Freitas LT. Atuação do farmacêutico na dispensação de antimicrobianos com foco na resistência bacteriana. Brazilian Journal of Development 2021;7(5): 4823448244 .

25. Silva SJC, Souza FCR, Aoyama EA. A incidência do uso indiscriminado de medicamentos. Revista Brasileira Interdisciplinar de Saúde 2020; v.2: n.I, p.95-99.

26. Souza MNC, et al. Ocorrência de Automedicação na população brasileira como estratégia preventiva da SARS-CoV-2. Revista Pesquisa- Sociedade e Desenvolvimento 202I. V.IO: $\mathrm{n}^{\mathrm{O}} \mathrm{I}, \mathrm{p} . \mathrm{I}^{-} \mathrm{g}$.

27. Correia BC, Trindade JK, Almeida AB. Fatores correlacionados á automedicação entre os jovens e adultos: uma revisão integrativa da literatura. Revista de Iniciação Científica e Extensão - REIcEn 2019. v.2: n.I, p.57-6r.

28. Gimenes LS, et al. A influência da propaganda de medicamentos na automedicação. Revista Amazônia Science \& Health 2019. v.7: n.2, p.I4-19. 
29. Rodrigues AC. Utilização de medicamentos isentos de prescrição e economias geradas para os sistemas de saúde: uma revisão. Revista Brasileira de Economia da Saúde 2017. v.9: n.I, p.128-136.

30. Loureiro RJ, et al. O uso de antibióticos e as resistências bacterianas: breves notas sobre a sua evolução. Revista Portuguesa de Saúde Pública 2or6. v.34: n.I, p.77-84.

31. Gonçalves CA, et al. Intoxicação medicamentosa: relacionada ao uso indiscriminado de medicamentos. Revista Científica da Faculdade de Educação e Meio Ambiente FAEMA. 2017. v.8: n.I, p.135-143.

32. Carvalho W, Guimarães AS. Desinformação, Negacionismo e Automedicação: a relação da população com as drogas "milagrosas" em meio à pandemia da COVID19. Inter American Journal of Medicine and Health 2020. v.3: n응, p.I-I5.

33. Gomes AHD, et al. Risco da automedicação na pandemia por COVID-ı: O dilema entre informações midiáticas e científicas. Ceará: Editora ampla; 2020.

34. CONCEIÇÃO, M.F. Uso de hidroxicloroquina/cloroquina e azitromicina., DOE no Io8., Deliberação CIB no 45., 2020.

35. MELO, J.R.R.; DUARTE, E.C.; MORAES, M.V.; FLECK, K.; ARRAIS, P.S.D. Automedicação e uso indiscriminado de medicamentos durante a pandemia da COVID-r9., CSP Cardemos de Saúde Pública., v.37, nº 4, p.I-5., 2021.

36. SILVA, A.F.; JESUS, J.S.P.; RODRIGUES, J.L.G. Automedicação na pandemia do novo coronavírus., Revista Ibero - Americana de humanidades, Ciências e Educação., v.7, no-4. P.938-943., 2021.

37. MALIK, M.; TAHIR, M.J.; JABBAR, R.; AHMED, A.; HUSSAIN, R. Automedicação durante a pandemia de COVID-ig: desafios e oportunidades., Perspectivas de medicamentos e terapias., V.I, $\mathrm{n}^{\mathrm{O}} \mathrm{I}, \mathrm{P} . \mathrm{I}-3$. , 2020.

38. ZHANG, A.; HOBMAN E.V.; BARRO P.; YOUNG A.; CARTER D.J.; BYRNE M. Automedicação com antibióticos para proteção contra COVID-I9: o papel do sofrimento psicológico, conhecimento e experiências com antibióticos., Antibiotics., v.Io, n.I, p.I-I4., 202I.

39. SADIO, A.J.; KOMLANVI, F.A.G.; KONU, R.Y.; BAKOUBAYI, A.W.; TCHANKONI, M.K.; ANDERSON, A.M.B.; GOMEZ, I.M.; DENADOU, C.P.; ANANI, J.; KOUANFACK, H.R.; KPETO, I.K.; SALOU, M.; EKOUEVI, D.K. 
Avaliação das praticas da automedicação em contexto do surto COVID-19., BMC Public Health., v.21. nº-58, p.I-9., 2021.

40. OLIVEIRA, J.V.L.; COSTA, F.B.; PORFIRIO.V.N.; SILVA.M.M.M.; CUNHA.A.B.O.C.; SILVA.N.C.; NASCIMENTO.V.J.O.A.; FRANÇA.A.M.M.; MELO.M.L.R.S.; SILVA.R.F.C.; COSTA.M.D.T.; FILHO.L.S.S.; Automedicação no período de pandemia de COVID-ı: revisão integrativa.; Research, Society andDevelopment.; v.10, nํㅜㄱ, p.I-II., 2021.

41. CRUZ, M.P.; SANTOS, E.; CERVANTES, M.A.V.; JUÁREZ, M.L. COVID-r9, uma emergência global de saúde pública., Revista clínica espanhola, ELSEVIER., v.22I, nํㅡㄴ, 55-61., 2021.

42. MEJÍRA, P.J.N.; GERRERO, J.C.V.; CHERO, L.L. Automedicação em tempos de pandemia: COVID-ı., Revista HNAAA Medical Corps., v.13, no4, p.350-355., 2020. 